\title{
Primary and Isolated Adult T-cell Leukemia/lymphoma of the Bone Marrow
}

\author{
Tohru Takahashi, Hiroyuki Tsukuda, Hideto Itoh, Hirokazu Kimura, \\ Mitsuru Yoshimoto and Masayuki Tsujisaki
}

\begin{abstract}
The distribution of adult T-cell leukemia/lymphoma (ATLL) is typically systemic. In addition to peripheral blood (PB) and lymph nodes, extranodal sites such as the skin, lung, liver, gastrointestinal tract, and central nervous system are frequently involved. We report a unique case of ATLL in which the patient presented with prolonged fever. A 65-year-old man had high-grade fever lasting for 2 weeks. He showed no lymphadenopathy, hepatosplenomegaly, skin lesions, or PB involvement. Bone marrow examination showed widespread infiltration of ATLL cells. ${ }^{18}$ F-fluorodeoxy glucose positron emission tomography (FDG-PET) revealed that the disease was confined to the bone marrow.
\end{abstract}

Key words: adult T-cell leukemia/lymphoma, bone marrow

(Intern Med 50: 2393-2396, 2011)

(DOI: 10.2169/internalmedicine.50.5857)

\section{Introduction}

Adult T-cell leukemia/lymphoma (ATLL) is endemic in Japan, the Caribbean, Melanesia, and parts of Africa. It is related to the infection of human T-lymphotropic virus-I (HTLV-I). Most ATLL patients present with widespread lymph node involvement as well as PB involvement. Hypercalcemia with or without lytic bone lesions and cutaneous lesions, including erythematous rashes, papules and nodules, are common features observed in the course of ATLL. Opportunistic infections such as Pneumocystis jirovecii pneumonia and strongyloidiasis are observed in many patients with ATLL (1).

Here, we report a unique case of ATLL presenting with prolonged fever. The patient showed no lymphadenopathy, hepatosplenomegaly, skin lesions, hypercalcemia, or PB involvement. The result of ${ }^{18} \mathrm{~F}$-fluorodeoxy glucose positron emission tomography (FDG-PET) and bone marrow examination showed that the disease was confined to the bone marrow.

\section{Case Report}

A 65-year-old man was admitted to our hospital in September 2008 because of high-grade fever lasting for two weeks. He had no remarkable medical history. Upon physical examination, his superficial lymph nodes, liver, and spleen, were not palpable. He had no skin lesions, no neurological deficit was observed and his body temperature was $39.3^{\circ} \mathrm{C}$.

The patient's white cell count was $13,060 / \mu \mathrm{L}$, with $77.5 \%$ neutrophils, $15.0 \%$ lymphocytes, and $7.5 \%$ monocytes. There were no flower-like cells or abnormal lymphocytes in the peripheral blood. His red blood cell count was $3.65 \times 10^{6} \%$ $\mu \mathrm{L}$, with $1.3 \%$ reticulocytes, hemoglobin concentration of $10.5 \mathrm{~g} / \mathrm{dL}$, and platelet count of $410,000 / \mu \mathrm{L}$. The serum biochemistry test results were as follows: total protein, $6.3 \mathrm{~g} / \mathrm{dL}$ (reference range, 6.7-8.3 g/dL): albumin, $3.2 \mathrm{~g} / \mathrm{dL}(3.8-5.3$ $\mathrm{g} / \mathrm{dL})$ : total bilirubin $0.4 \mathrm{~g} / \mathrm{dL}(0.2-1.1 \mathrm{~g} / \mathrm{dL}):$ AST $106 \mathrm{IU} / \mathrm{L}$ (10-40 IU/L), ALT $35 \mathrm{IU} / \mathrm{L}$ (5-45 IU/L): and LDH 5,016 IU/L (115-245 IU/L). The level of calcium in the serum was not elevated $(9.0 \mathrm{mg} / \mathrm{dL})$. C-reactive protein level was 19.92 $\mathrm{mg} / \mathrm{dL}(\leq 0.30)$. Serum ferritin level was $14,158.0 \mathrm{ng} / \mathrm{mL}$ (reference range, $5-152 \mathrm{ng} / \mathrm{mL}$ ). Soluble IL-2 receptor level 


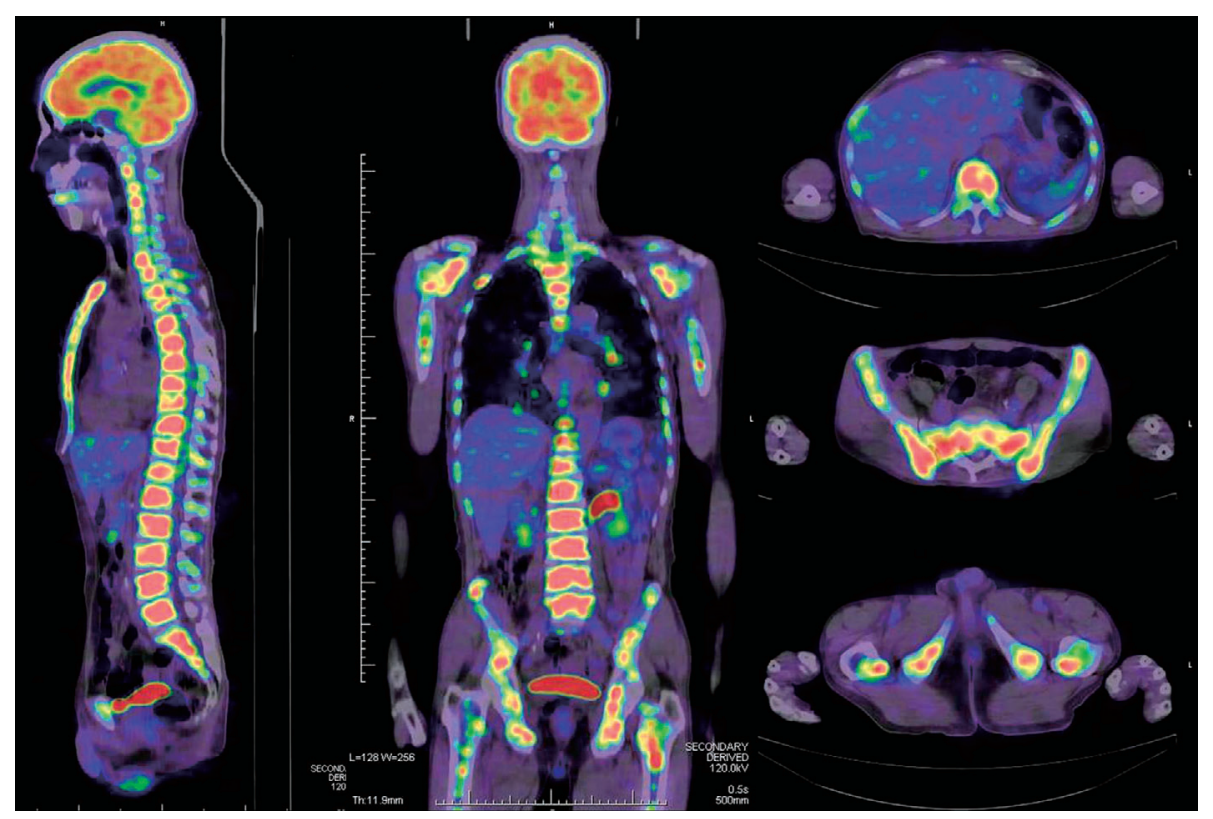

Figure 1. An FDG-PET study with a simultaneous whole-body CT scan. Markedly increased uptake of FDG in the vertebra, humeri, femora, sternum, and iliac bones.
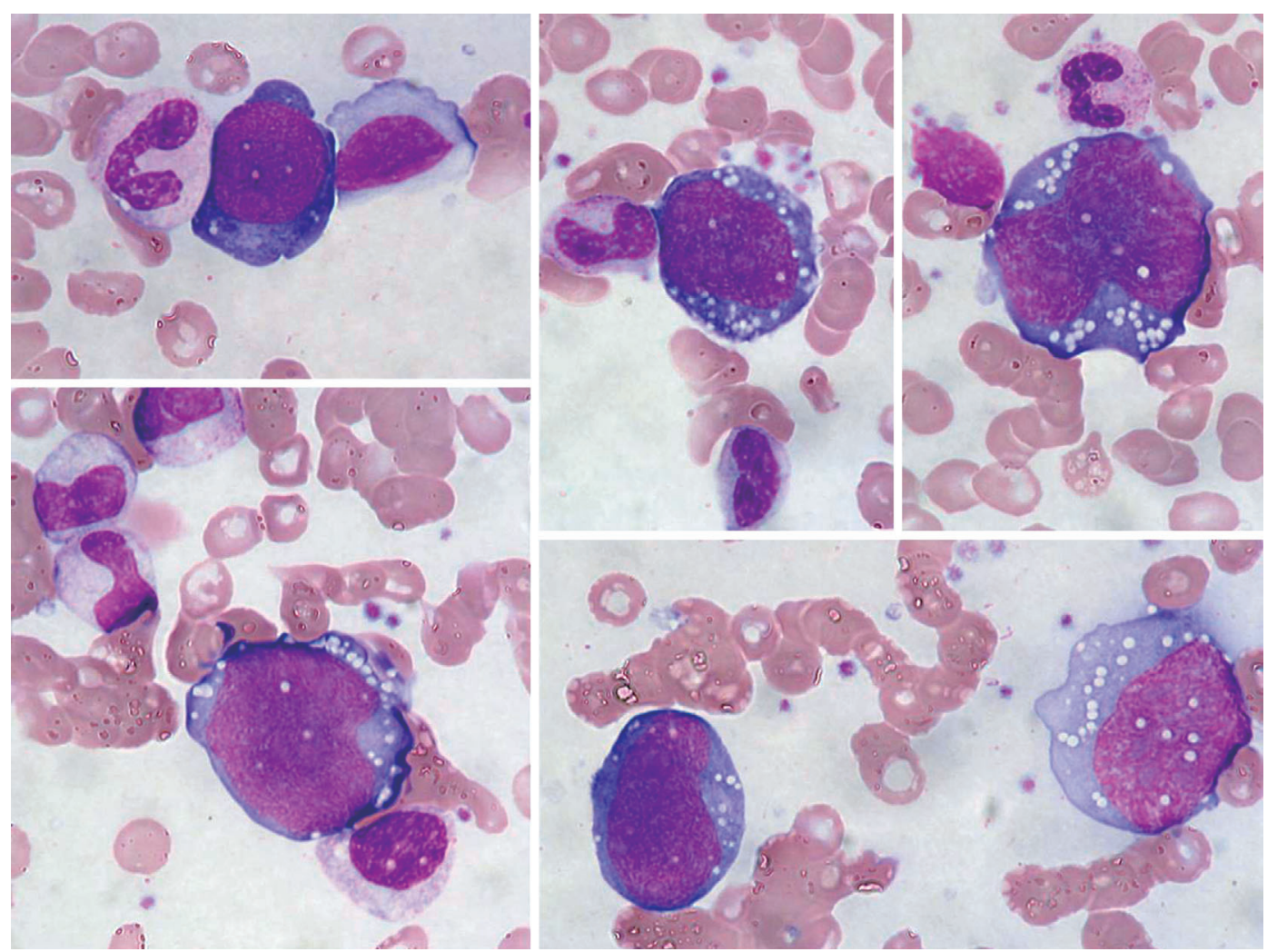

Figure 2. Bone marrow aspiration (May-Giemsa staining). Large unusual lymphoid cells with inconspicuous nucleoli, basophilic cytoplasm, and cytoplasmic vacuoles.

was $28,106 \mathrm{U} / \mathrm{mL}$ (reference range, $135-483 \mathrm{U} / \mathrm{mL}$ ). AntiHTLV-I antibody was $8,192 \times(\leq 16 \times)$

An FDG-PET study with a simultaneous whole-body CT scan showed a markedly increased uptake of FDG in the vertebra, humeri, femora, sternum, and iliac bones (Fig. 1). No hepatosplenomegaly or increased uptake of FDG in the liver or spleen was observed. Bone roentgenograms showed no osteolytic lesions. Thus, we considered that the tumorous lesions were confined to the bone marrow.

Bone marrow aspiration showed proliferation of large unusual lymphoid cells with inconspicuous nucleoli, basophilic cytoplasm, and cytoplasmic vacuoles (Fig. 2). Cell surface marker analysis showed that these cells were positive for $\mathrm{CD} 2, \mathrm{CD} 4, \mathrm{CD} 5, \mathrm{CD} 15, \mathrm{CD} 25$, and CD30, and that they 
were negative for CD3, CD7, CD8, CD10, CD16, CD19, CD20, CD23, and CD56. Bone marrow trephine biopsy showed massive widespread infiltration of large atypical lymphoid cells (Fig. 3). Immunohistochemical analyses showed that the cells were positive for CD3, CD5, CD30, and $\mathrm{Bcl}-2$, and that they were negative for CD10 and CD20 (Fig. 4). Chromosomal analysis of the bone marrow cells showed that 5 of 20 cells analyzed showed complex hypotetraploid chromosomal abnormalities, including $86, \mathrm{XX},-\mathrm{Y}$,

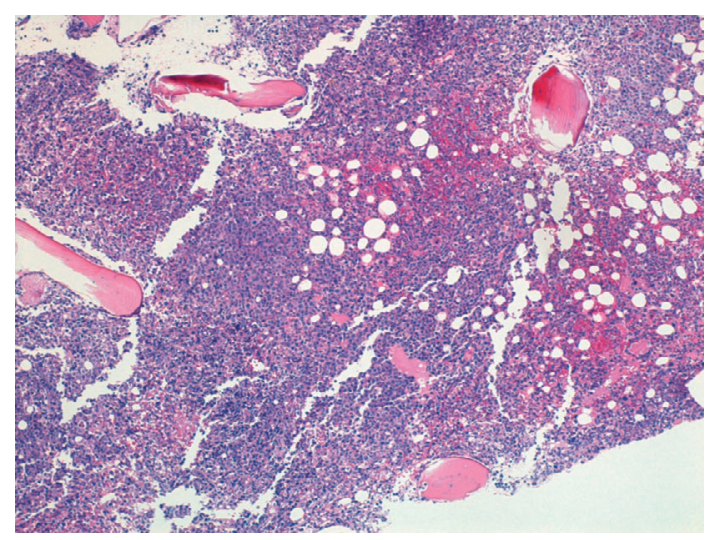

Figure 3. Bone marrow biopsy (Hematoxylin and Eosin staining). Massive widespread infiltration of large atypical lymphoid cells in the bone marrow.
$-\mathrm{Y},+\mathrm{X}, \operatorname{add}(1)(\mathrm{p} 11) \times 2,+\operatorname{add}(1)(\mathrm{q} 21),-4,-4, \operatorname{add}(5)(\mathrm{p} 13),-6$, $\operatorname{add}(6)(\mathrm{q} 13), \operatorname{der}(6) \operatorname{del}(6)(\mathrm{p} 22) \operatorname{add}(6)(\mathrm{q} 21) 2, \operatorname{add}(12)(\mathrm{p} 11.2)$, $-13, \operatorname{add}(13)(\mathrm{q} 22),-14,-14,-15,-17,-17, \mathrm{i}(18)(\mathrm{q} 10) \times 2,-19$, $-19, \operatorname{del}(21)(\mathrm{q} 22) \times 2,-22,-22,+9$ mar. Monoclonal proliferation of marrow tumor cells was confirmed using Southern blot analysis with probes for HTLV-I pro-virus. Thus, we diagnosed the patient as having ATLL.

The patient was treated using the LSG15 protocol, which consisted of 7 cycles of VCAP (vincristine, cyclophosphamide, doxorubicin and prednisone), AMP (doxorubicin, ranimustine and prednisone) and VECP (vindesine, etoposide, carboplatin and prednisone) (2). After the first cycle of treatment, the pyrexia subsided and laboratory data normalized. Bone marrow examination after 2 cycles of the therapy showed no detectable tumor cells. After completion of the seventh cycle of therapy in July 2009, the disease recurred with high-grade fever and elevated LDH levels. Subtle cutaneous lesions and mild lymphadenopathy in the neck, which were potentially caused by tumor involvement were observed at that time, but the tumor cells did not emerge in PB. Dexamethasone, sobuzoxane, etoposide, or pentostatin were used with minimal success. The patient died of the disease progression in December 2009.
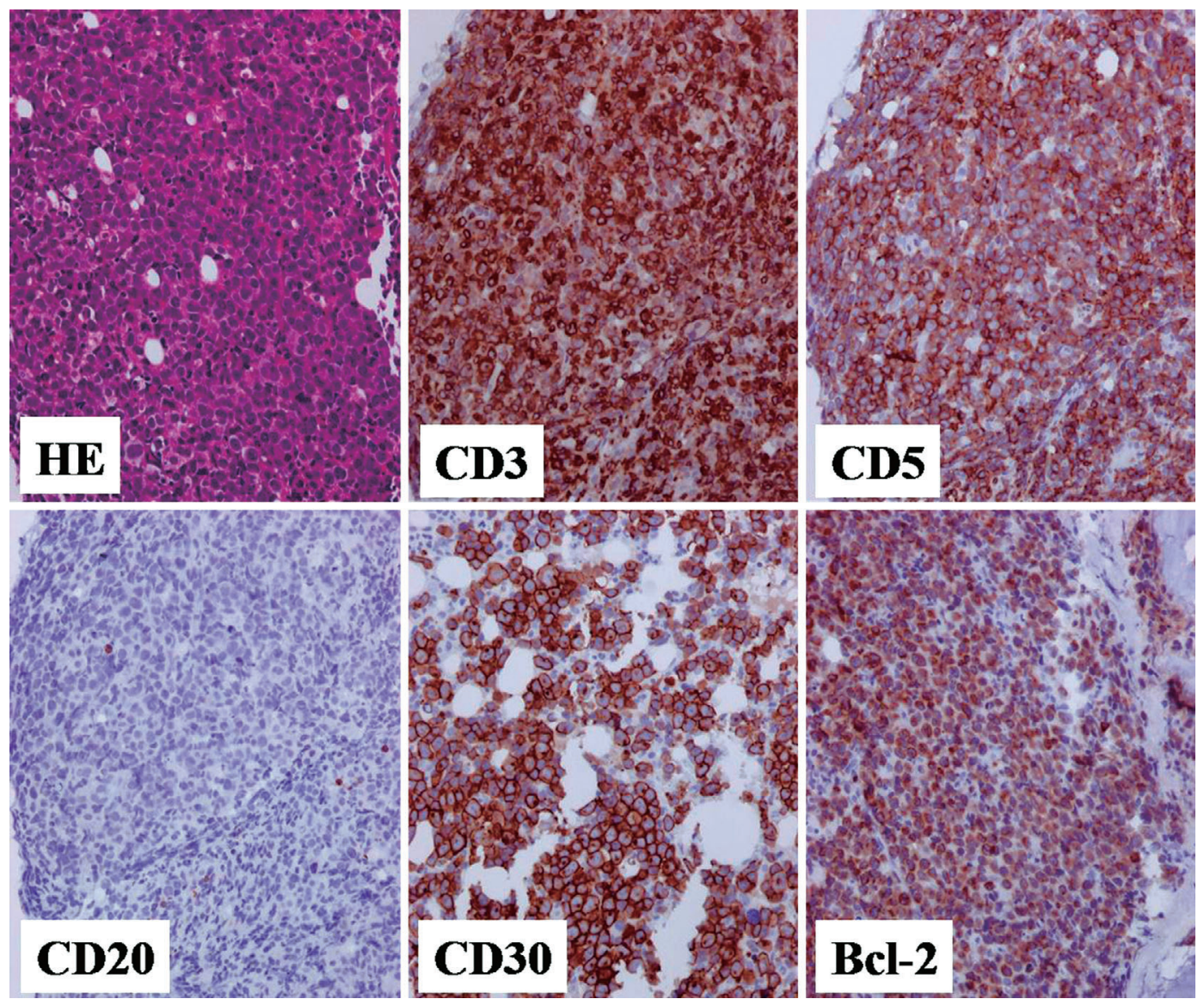

Figure 4. Immunohistochemical analysis of bone marrow. The tumor cells were positive for CD3, CD5, CD30, and Bcl-2, and they were negative for CD20. 


\section{Discussion}

The distribution of ATLL is typically systemic. In addition to PB and lymph nodes, the disease also affects extranodal sites such as the skin, lung, liver, gastrointestinal tract, and central nervous system (3). Several clinical variants of this disease, including acute, lymphomatous, chronic, and smoldering ATLL, have been described to date (4). The acute-type ATLL is the most common variant and is characterized by a leukemic phase, typically with a markedly elevated white blood cell (WBC) count, skin rash, and widespread lymphadenopathy. The lymphomatous type is characterized by prominent lymphadenopathy but without PB involvement. Cutaneous lesions are common in both acute and lymphomatous forms of ATLL. Since there were no circulating tumor cells, skin lesions, and lymphadenopathy, the present case does not appear to be a typical ATLL subtype. However, this case can be categorized as acute-type ATLL because the diagnosis of acute type ATLL was made by excluding other types. This case was aggressive, therefore the patient was initially treated with intensive chemotherapy (LSG15 protocol).

ATLL cells were confined to the bone marrow in the present case. Microscopic examination of a smear specimen showed that PB was not involved, although cell surface marker analysis of PB lymphocytes was not performed. FDG-PET analysis confirmed that other sites were not involved at presentation. Bone marrow involvement is commonly observed in patients with lymphoma and is typically detected at an advanced stage of the disease. However, primary bone marrow lymphoma is rare (5-10). Clinical manifestation, treatment, and prognosis are not well defined, and diagnosis is based on bone marrow biopsy.

In 8 of the 14 cases subjected to cell characterization, marrow lymphoma originated in T-cells, including a case of ALK-negative CD30 positive anaplastic large cell lymphoma (ALCL) (10). In the present case, tumor cells were also positive for CD30. Large transformed cells of ATLL may be positive for CD30; an ATLL case in which the pathological diagnosis was identical to that of ALCL has also been reported (11). Most marrow lymphoma patients experience bicytopenia or pancytopenia and are referred to a hospital for prolonged fever or fever of unknown origin. Our patient also experienced prolonged fever, but he had only mild anemia upon admission.

In a small portion of ATLL patients, bone lesions are observed in the tibia, ulna, scapula, femur, and clavicle. Rare cases of primary ATLL in bone have also been reported $(12,13)$. In one case, the tumor cells produced MIP$1 \alpha$ that enhanced expression of RANKL of local osteoblasts and stromal cells (13). The mechanism of tumor cell confinement to the marrow in cases of primary bone marrow lymphoma, remains to be elucidated. We hypothesize that tumor cells are dependent on cognate survival signals from bone marrow stromal cells via cell-adhesion molecules.

There have been no previous reports of primary and isolated marrow ATLL. ATLL may be a causative disease for prolonged fever even when PB involvement, lymphadenopathy, hepatosplenomegaly, or skin rash are absent.

\section{The authors state that they have no Conflict of Interest (COI).}

\section{References}

1. Ohshima K, Jaffe ES, Kikuchi M. Adult T-cell leukaemia/lymphoma. In: WHO Classification of Tumours of Haematopoietic and Lymphoid Tissues. Swerdlow SH, Campo E, Harris NL, et al, Eds. IARC Press, Lyon, France, 2008: 281-284.

2. Yamada Y, Tomonaga M, Fukuda H, et al. A new G-CSFsupported combination chemotherapy, LSG15, for adult T-cell leukaemia-lymphoma: Japan Clinical Oncology Group Study 9303. Br J Haematol 13: 375-382, 2001.

3. Bunn PA Jr, Schechter GP, Jaffe E, et al. Clinical course of retrovirus-associated adult T-cell lymphoma in the United States. N Engl J Med 309: 257-264, 1983.

4. Shimoyama M. Diagnostic criteria and classification of clinical subtypes of adult T-cell leukaemia-lymphoma. A report from the Lymphoma Study Group (1984-87). Br J Haematol 79: 428-437, 1991.

5. Barton JC, Conrad ME, Vogler LB, Parmley RT. Isolated marrow lymphoma: an entity of possible T-cell derivation. Cancer 46: 1767-1774, 1980.

6. Hassan K, Nagi AH, Hayee A. Non-Hodgkin's lymphoma of bone marrow-an unusual presentation. J Pak Med Assoc 32: 230-236.

7. Ponzoni M, Li CY. Isolated bone marrow non-Hodgkin's lymphoma: a clinicopathologic study. Mayo Clin Proc 69: 37-43, 1994.

8. Chachashvili S, Almoznino-Sarafian D, Yona R, et al. Isolated bone marrow non-Hodgkin's lymphoma. Report of two cases and literature review. Eur J Intern Med 14: 116-119, 2003.

9. Alvares CL, Matutes E, Scully MA, et al. Isolated bone marrow involvement in diffuse large B cell lymphoma: a report of three cases with review of morphological, immunophenotypic and cytogenetic findings. Leuk Lymphoma 45: 769-775, 2004.

10. Gudgin E, Rashbass J, Pulford KJ, Erber WN. Primary and isolated anaplastic large cell lymphoma of the bone marrow. Leuk Lymphoma 46: 461-463, 2005.

11. Takahara T, Masutani K, Kajiwara E, et al. Adult T-cell leukemia/ lymphoma in which the pathohistological diagnosis was identical to that of $\mathrm{Ki}-1$ positive anaplastic large cell lymphoma. Intern Med 38: 824-828, 1999.

12. Takemoto S, Matsuoka M, Sakata K, et al. Primary adult T cell leukemia of bone: two patients with primary bone lesion showing monoclonal integration of HTLV-I proviral DNA. Leukemia 10: 333-337, 1996.

13. Hara T, Wakatsuki S, Ozaki S, Abe M, Kosaka M. Primary adult T-cell leukemia/lymphoma of bone. Int J Hematol 79: 157-160, 2004.

(C) 2011 The Japanese Society of Internal Medicine http://www.naika.or.jp/imindex.html 